\title{
Early differentation of lamellar structure of the intervertebral disc in staged human embryos
}

\author{
Witold Woźniak, Małgorzata Grzymisławska, Joanna Łupicka, Małgorzata Bruska, Adam \\ Piotrowski, Anna Gałązka, Magdalena Rojewska, Jarosław Sobański \\ Department of Anatomy, Poznan University of Medical Sciences, Poland
}

\begin{abstract}
Introduction. In the vast literature concerning the development of the intervertebral discs controversies exist as to the period of differentiation and structure of the nucleus pulposus and annulus fibrosus. These controversies result from different determination of age of the investigated embryos.

Aim. Using embryos from departmental collection age of which was established according to international Carnegie staging and expressed in postfertilizational days, the differentiation of the intervertebral discs was traced.

Material and methods. Study was performed on 34 embryos at developmental stages 13-23 (32-56 days). Embryos were serially sectioned in sagittal, frontal and horizontal planes. Sections were stained with various histological methods and impregnated with silver.

Results. Division of sclerotomes into loose cranial and dense caudal zones (sclerotomites) was observed in embryos aged 32 days (stage 13). The intervertebral disc developed from the dense zone of sclerotome and was well recognized in embryos aged 33 days (stage 14). At the end of fifth week (embryos at stage 15, 36 days) the annulus fibrosus and the nucleus pulposus were seen. The annulus fibrosus differentiated into lateral and medial zones. Within the lateral zone cells were arranged into circular rows. These rows were considered as the first stage of laminar structure. In further developmental stages the laminae occupied both zones of the annulus fibrosus. Conclusions. The intervertebral discs develop from the dense zone of the sclerotome which is evident in embryos at stage 13 (32 days). Discs differentiate in embryos aged 33 days, when the nucleus pulposus and annulus fibrosus are recognized. In embryos aged 36 days in the annulus fibrosus circular rows forming laminar arrangement are seen.
\end{abstract}

Keywords: human embryology, intervertebral disc, annulus fibrosus.

\section{Introduction}

The intervertebral disc is a moderately movable joint that separates the vertebrae of the vertebral column [1]. The disc was first recognized as an anatomical entity by Vesalius and together with its subjacent vertebral bodies and associated ligaments it constitutes the vertebral unit [2].

The adult intervertebral disc is an avascular fibrocartilage tissue with a small population of cells that obtain nutrients from the capillaries at the vertebraldisc body interface [3].
Nutrients diffuse from capillaries to the disc cells and metabolities produced then diffuse from the cells through the matrix to the blood supply [4].

The disc is composed of a nucleus pulposus, which occupies the center of the disc, and an outer zone, annulus fibrosus consisting of a series of lamellae of collagenous bundles, which are arranged spirally.

The disc vertebral-interface of cartilage endplate is considered by some authors as a separate third structure of the intervertebral disc $[5,6]$. 
Each of these tissues has a different function and consists of a specific matrix structure that is maintained by distinct cell populations [1].

The nucleus pulposus is hydrated semigelatinous tissue which contains fine bundles of collagenous fibers, type II connective tissue cells, and chondrocyte-like cells, embedded in amorphous intercellular matrix containing hydrophilic proteoglycans which retain water and provide strength and spongy features to the disc [2]. It is predominantly made up of water (70-90\% depending on the age). Collagenous fibers constite ca. $20 \%$ of dry weight and proteoglycans ca. $50 \%$ of dry weight [7]. However, tissue of nucleus pulposus is different from hyaline cartilage due to the ratio between proteoglycan and collagen. This ratio within the nucleus pulposus is $27: 1$, whereas in cartilaginous endplate it is $2: 1[1,8]$.

The annulus fibrosus is organized in fibrous ring-like lamellae and it surrounds the nucleus pulposus. It may be divided into inner and outer zones and is attached to the vertebrae at the superior and inferior surfaces as well as is also connected to anterior and posterior longitudinal ligaments. The thickness of the lamellae increases from the outer to inner layers [9].

The annulus fibrosus is composed principally of water (60-80\%, depending on the region and age), collagen (50-70\% of dry weight), aggregating and nonaggregating proteoglycans (10-20\% of dry weight) and noncollagenous proteins (ca. $25 \%$ of dry weight) [1].

Within each lamella collagen fibers are lying parallel [9]. In addition to the collagen network, a network of elastin fibers is present between the lamellae [10].

The cartilaginous endplate is composed of an osseous and a cartilaginous part. The main component of the endplate is water $(80 \%$ after birth, and $70 \%$ after 15 years age), followed by type II collagenous fibers and proteoglycans [1]. The thickness of the human endplate is $0.5-1 \mathrm{~mm}$ at the periphery and diminishes toward the center. It has a semi-permeable barrier and load-bearing functions [1].

The development of the intervertebral disc in human has been investigated by many authors [11-15].

There are many controversies in literature as to the contribution of loose and dense zones of sclerotomes and perinotochordal sheath to the development of the intervertebral disc. Different opinions also exist considering early differentiation of the annulus fibrosus and nucleus pulposus. It seems not amiss, therefore, to present the development of the intervertebral disc in staged human embryos with particular consideration of the annulus fibrosus.
Knowledge of the embryonic development of the intervertebral disc is important in understanding the adult regeneration of the disc. Such developmental studies are also needed to elucidate problems of chronic back pains connected with disc degeneration.

\section{Material and methods}

Study was made on 34 serially sectioned human embryos of developmental stages 13-23 from the Collection of the Department of Anatomy, Poznan University of Medical Sciences. Age of embryos was established according to 23 international stages and was expressed in postfertilizational days (Table 1). Embryos were cut in sagittal, frontal and horizontal planes.

Serial sections of 5 or 10 micrometers thickness were stained according to following methods: 1) hematoxylin and eosin, 2) Nissl's toluidine blue or cresyl violet, 3) Mallory's trichrome, 4) Bodian's protargol.

In each developmental stage the graphic reconstructions, based on sections, were made.

\section{Results}

In embryos at stage 13 (32 days) the notochord is a continuous, unconstructed rod and forms the central axis for the developing vertebral column. The number of somites is 36 and they differentiate into sclerotomes, myotomes and dermatomes. The division of sclerotomes into loose, cranial and dense, caudal zones commences. These zones are also called sclerotomites. Intrasclerotomic fissures are distinctly seen and the loose cranial sclerotomite is traversed by the intersegmental artery and spinal nerve (Figure 1). Spinal ganglia which develop from the neural crest are seen and they are in contact with the neural crest. Ventral and dorsal roots of spinal nerves appear and the spinal nerves develop (Figure 2). The notochord is in the centers of sclerotomes and it possesses perinotochordal sheath formed by cells spreading out from the sclerotomes.

In embryos at stage 14 (33 days) caudal sclerotomites are more condensed than their cranial counterparts. The perinotochordal sheath consists of two layers and in this cellular sheath the dense and loose zones appear (Figure 3). The loose, cranial zone is the primordium of the vertebral centrum which is the precursor of the vertebral body. Intrasclerotomic fissures are present. Caudal sclerotomites are more condensed and they form intervertebral discs (Figure 4) and neural arches as well as their processes. The notochord presents a con- 
Table 1. Crown-rump length, development al stage and age in days of investigated embryos

\begin{tabular}{|c|c|c|c|c|}
\hline Catalogue number & Crown-rump lenght in $\mathrm{mm}$ & Developmental stage & Age in days & Plane of section \\
\hline B 171 & 4.0 & 13 & 32 & Frontal \\
\hline B 202 & 4.0 & 13 & 32 & Horizontal \\
\hline B 203 & 5.0 & 13 & 32 & Sagittal \\
\hline B 206 & 5.5 & 13 & 32 & Horizontal \\
\hline A 13 & 7.0 & 14 & 33 & Sagittal \\
\hline A 19 & 7.0 & 14 & 32 & Horizontal \\
\hline PJK 20 & 7.0 & 15 & 36 & Frontal \\
\hline PJK 18 & 9.0 & 15 & 36 & Frontal \\
\hline B 69 & 9.0 & 15 & 36 & Sagittal \\
\hline B 181 & 10.0 & 16 & 39 & Horizontal \\
\hline IV & 10.0 & 16 & 39 & Sagittal \\
\hline B 216 & 11.0 & 16 & 39 & Frontal \\
\hline B 67 & 12.5 & 17 & 41 & Sagittal \\
\hline B 64 & 13.5 & 17 & 41 & Frontal \\
\hline B 68 & 14.0 & 17 & 41 & Horizontal \\
\hline B 128 & 15.0 & 18 & 44 & Sagittal \\
\hline B 208 & 15.0 & 18 & 44 & Frontal \\
\hline$B \nmid 4$ & 15.0 & 18 & 44 & Horizontal \\
\hline B 100 & 16.0 & 18 & 44 & Sagittal \\
\hline B 66 & 16.5 & 19 & 46 & Horizontal \\
\hline Z 13 & 17.0 & 19 & 46 & Frontal \\
\hline B 123 & 17.5 & 19 & 46 & Sagittal \\
\hline A 10 & 18.0 & 19 & 46 & Horizontal \\
\hline KA 3 & 19.0 & 19 & 46 & Sagittal \\
\hline Bł 3 & 20.0 & 20 & 49 & Sagittal \\
\hline Z 19 & 21.0 & 20 & 49 & Horizontal \\
\hline A & 21.5 & 20 & 49 & Frontal \\
\hline B 127 & 23.5 & 21 & 51 & Sagittal \\
\hline A 4 & 23.5 & 21 & 51 & Frontal \\
\hline Z2 & 25.0 & 22 & 53 & Horizontal \\
\hline B 114 & 27.0 & 23 & 56 & Sagittal \\
\hline Kub 2 & 28.0 & 23 & 56 & Frontal \\
\hline B 177 & 28.5 & 23 & 56 & Horizontal \\
\hline Bł 11 & 29.0 & 23 & 56 & Frontal \\
\hline
\end{tabular}

tinuous, unconstricted rod surrounded by the perinotochordal sheath. It is widest in the lower cervical and upper thoracic parts.

It has to be pointed out that the term centrum is used for the central part of the vertebra and it ossifies from the primary center. The body of adult vertebra includes the centrum and a small part of the neural arch which unites at the neurocentral joint. The neural arch then is more extensive than adult vertebral arch. During stages 13 and 14 the vertical diameter of both sclerotomites is equal.

In embryos at stage 15 (36 days) and 16 (39 days) intrasclerotomic fissures disappear. Dense and loose zones of sclerotomes are well demarcated. This marked distinction between cranial and caudal sclerotomites is seen particularly in the cervical and thoracic parts (Figure 5). The notochord is not of uniform diameter throughout and is thicker in future discs. The perichordal centra surrounded by loosly distributed cells form the primordium of the vertebral body (Figure 6). In these centra cell density increases laterally in the vicinity of the spinal nerve. This is particularly evident in embryos at stage 17 (41 days), (Figure 7). In embryos at stage 15 in the annulus fibrosus of the intervertebral disc two zones may be distinguished. The medial zone, larger and close to the nucleus pulposus is formed of 


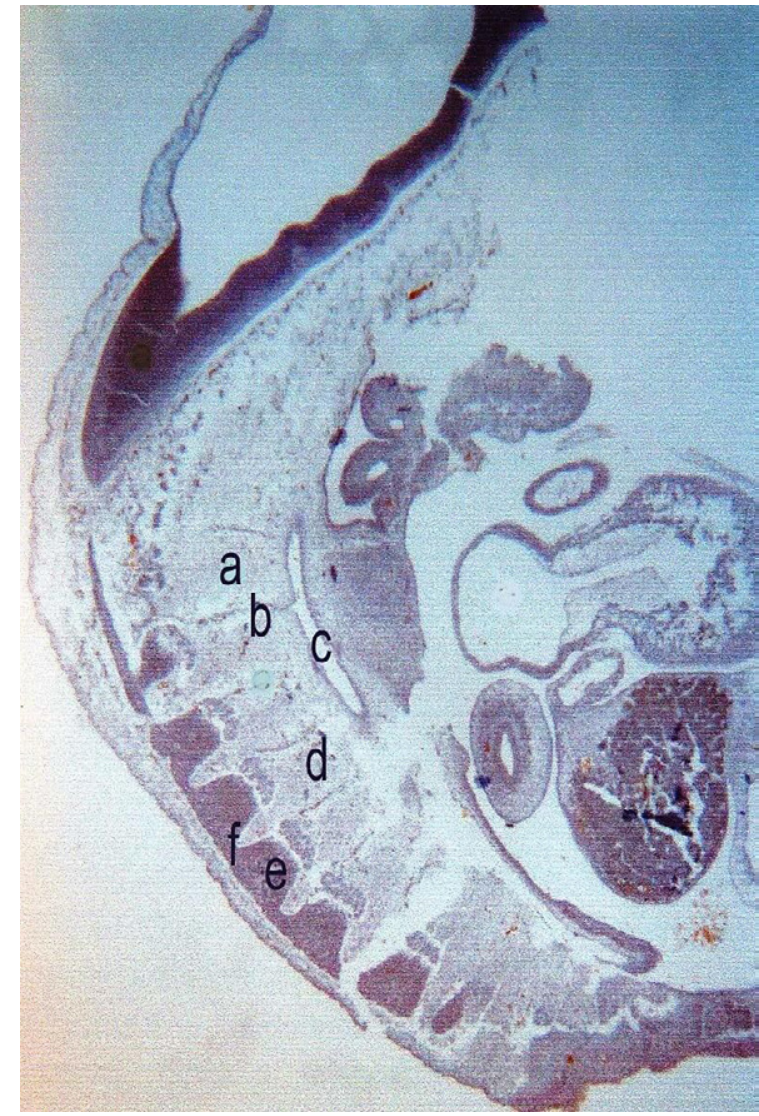

Figure 1. Sagittal section of human embryo at stage 13. Bodian's protargol, $x$ 100. a - dense zone of sclerotome, $b$ - loose zone of sclerotome, $\mathrm{c}$ - dorsal aorta, $\mathrm{d}$ - intersegmental artery, e - spinal ganglion, $f-$ neural crest

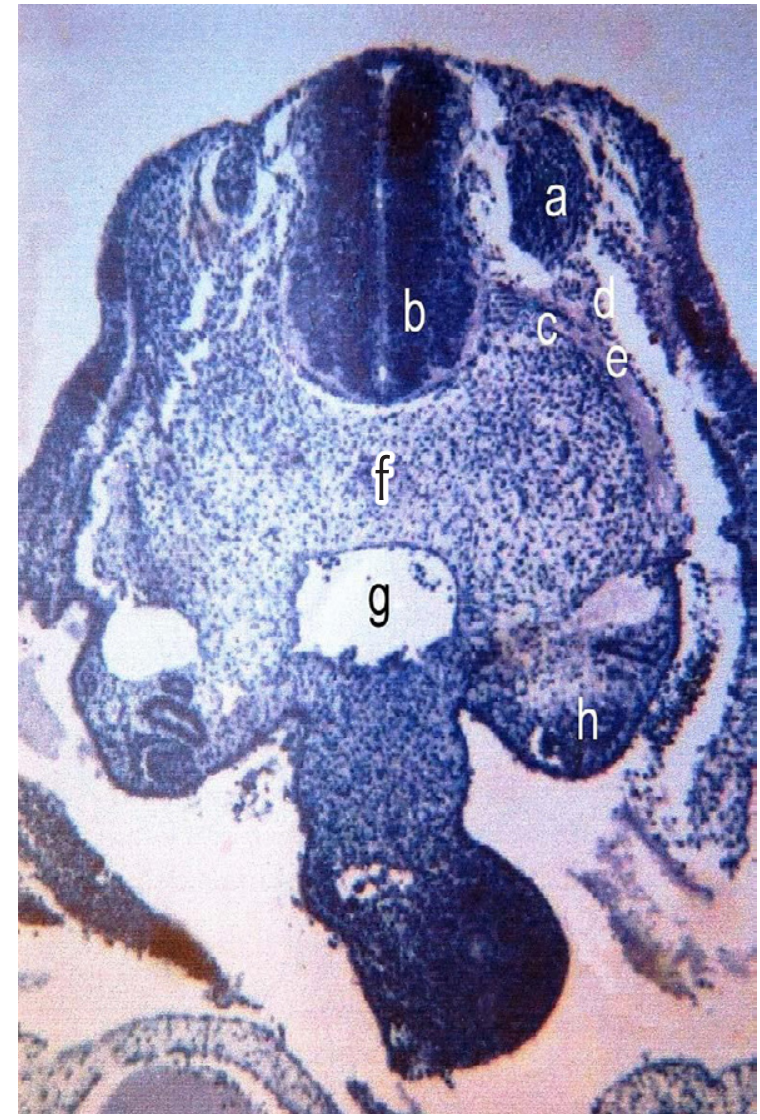

Figure 2. Horizontal section of embryo at stage 13. $\mathrm{H}+\mathrm{E}, \mathrm{x}$ 100. a - spinal ganglion, $b$ - spinal cord, $c$ - ventral root, $d$ - dorsal root, e - spinal nerve, $f$ - notochord with perinotochordal sheath, $g$ - dorsal aorta, $h$ - mesonephros

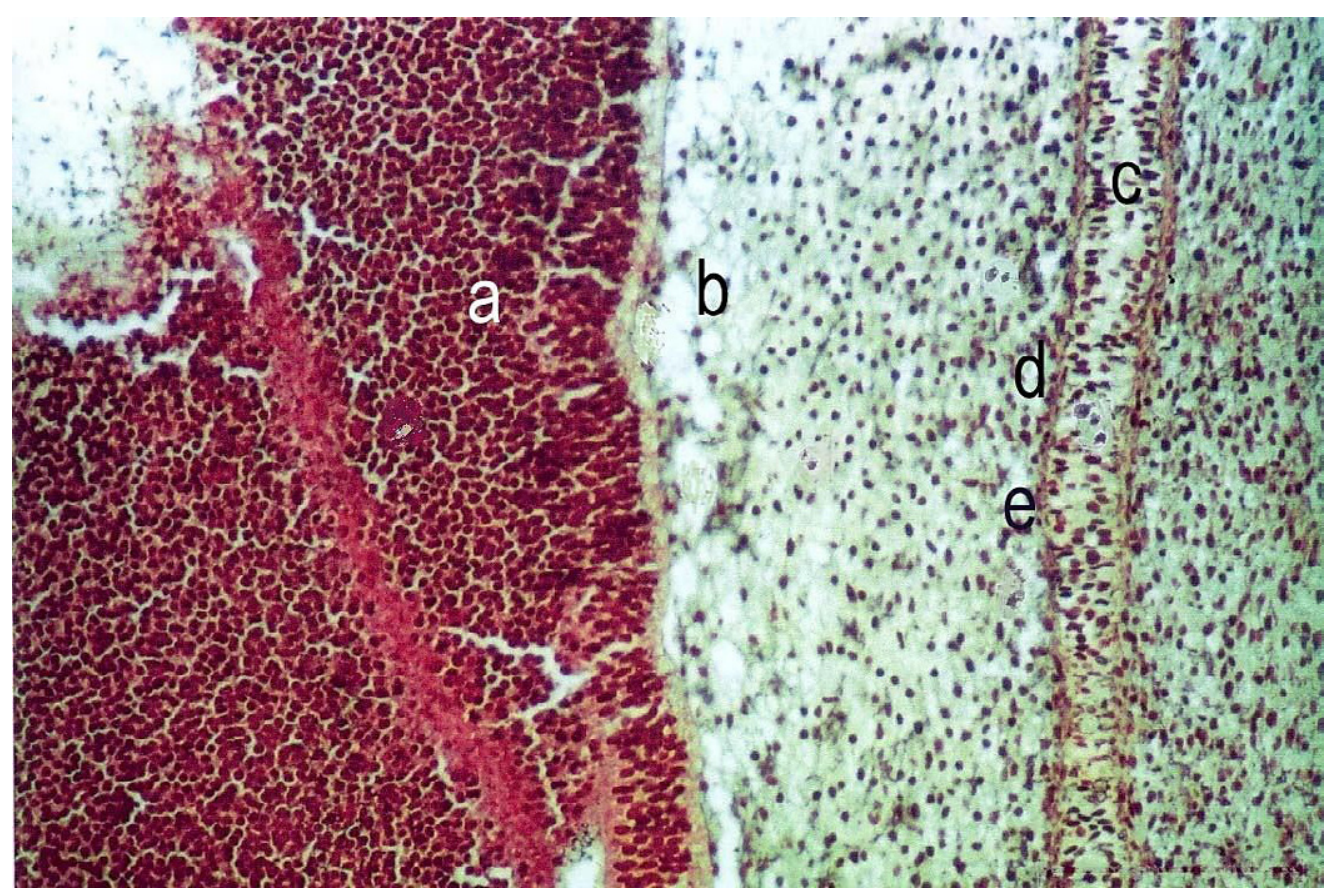

Figure 3. Sagittal section of embryo at stage 14. Bodian's protargol, x 300. a - spinal cord, b-primary meninx, c - notochord, $d$ - dense zone of perinotochordal sheath, $e-$ loose zone of perinotochordal sheath 


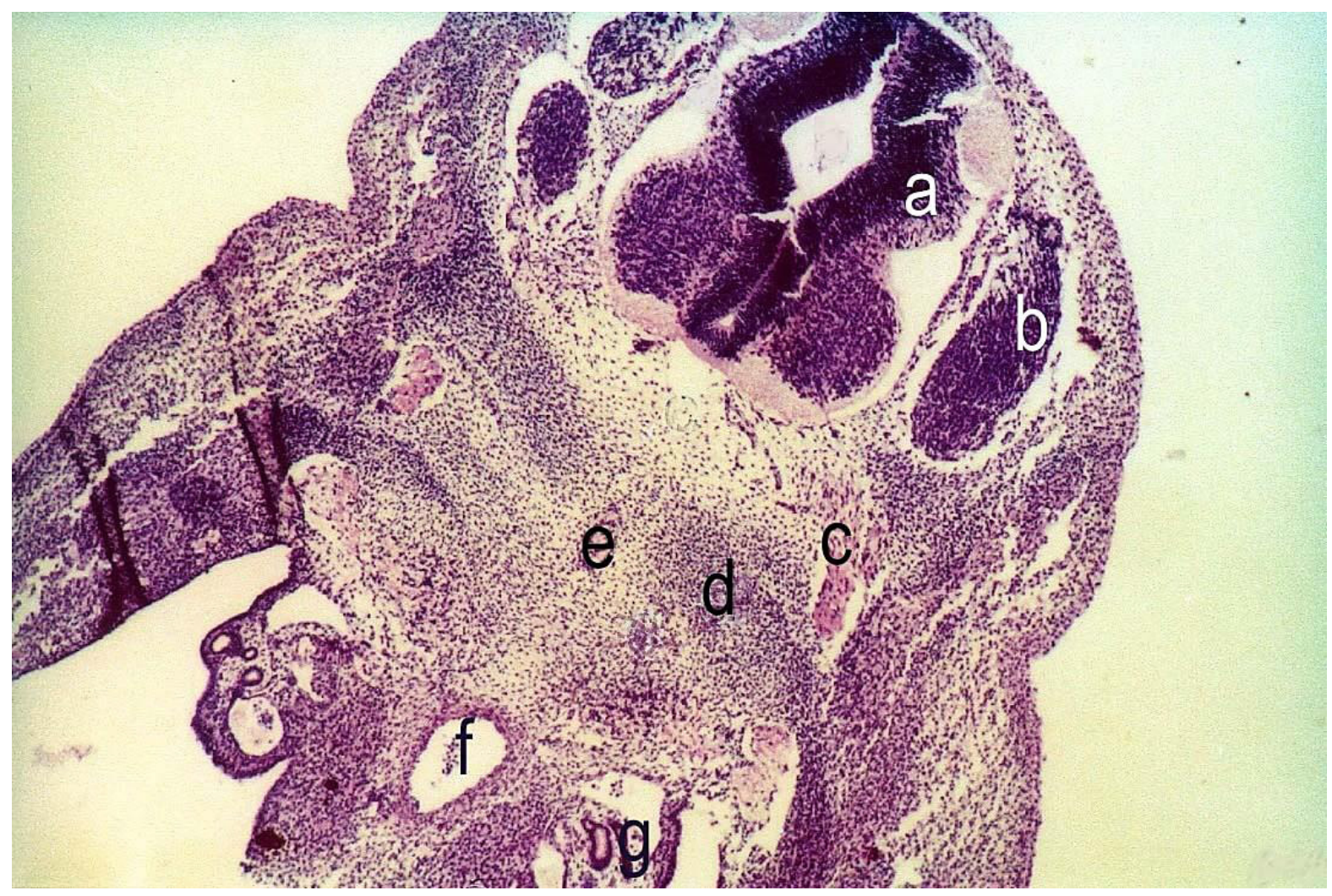

Figure 4. Horizontal section of embryo at stage 14. Cresyl violet, $x$ 100. a - spinal cord, b-spinal gangion, $c$ - spinal nerve, $d$ - intervertebral disc, $\mathrm{e}$ - notochord, $\mathrm{f}$ - dorsal aorta, $\mathrm{g}$ - mesonephros

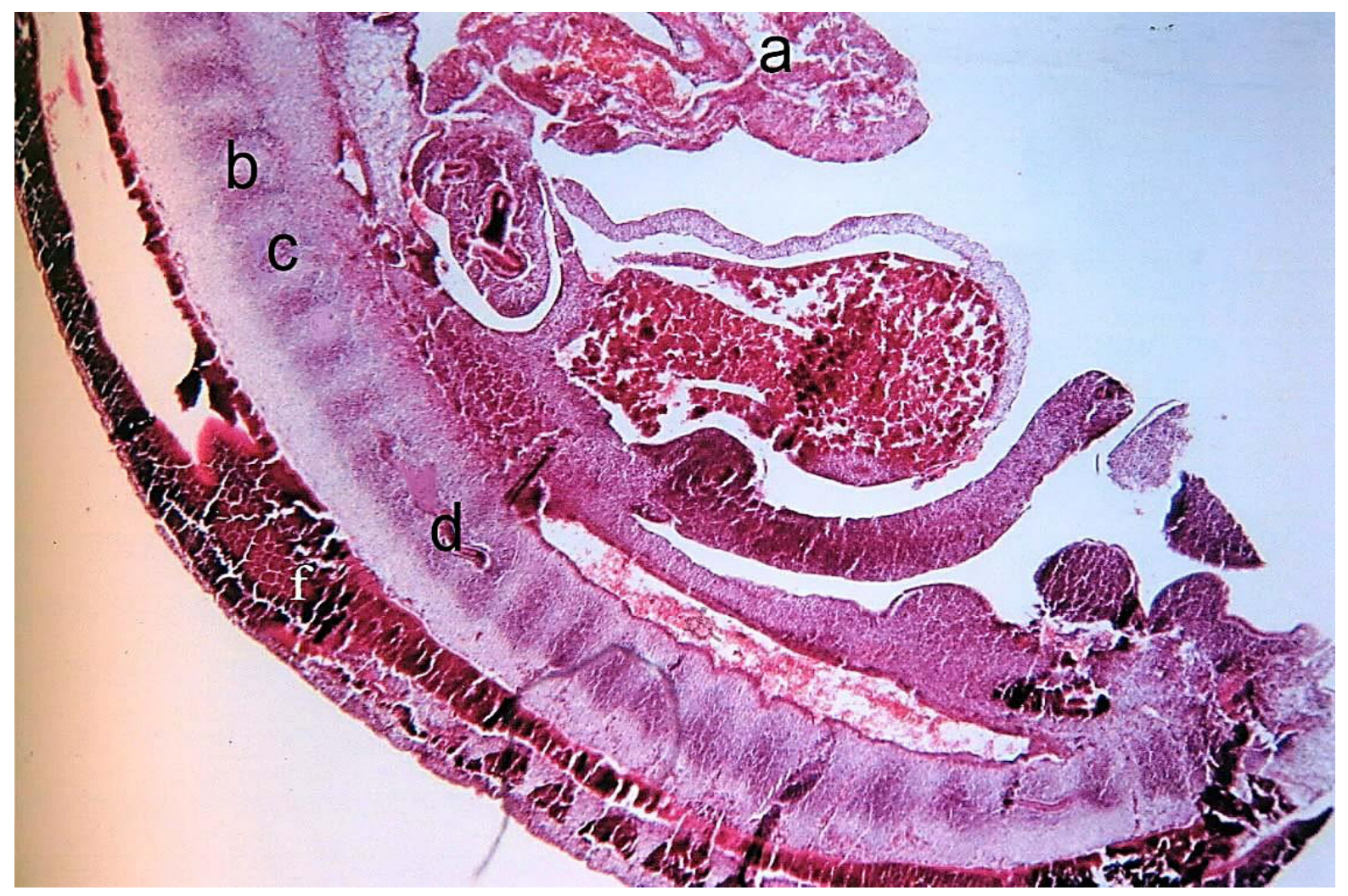

Figure 5. Sagittal section of embryo at stage $15 . \mathrm{H}+\mathrm{E}, \times 40$. a - heart, $\mathrm{b}$ - centrum of vertebra, $\mathrm{c}$ - intervertebral disc, e - notochord, $\mathrm{f}$ - spinal cord 


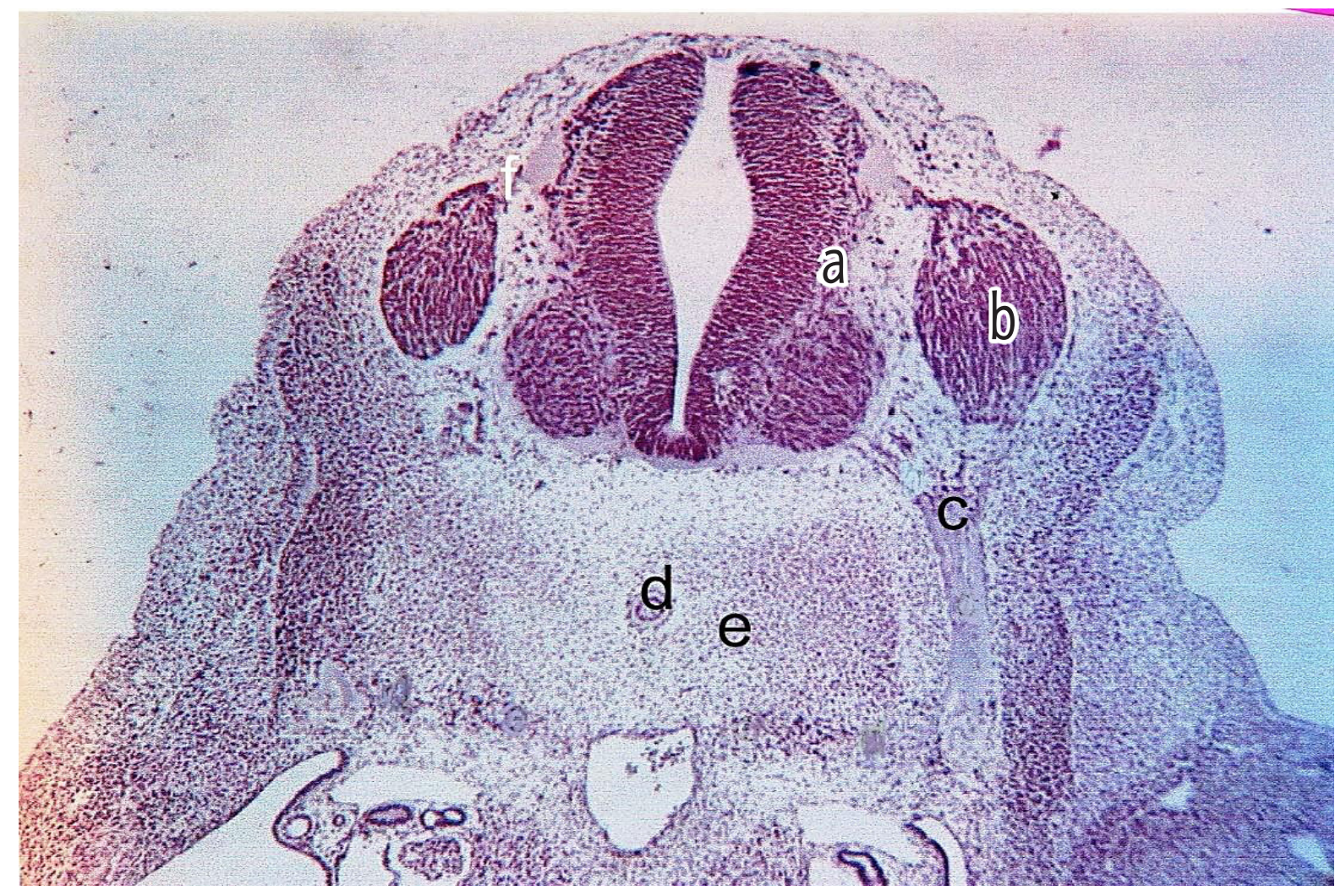

Figure 6. Horizontal section of embryo at stage 15. Bodian`s protargol, x 100. a - spinal cord, b-spinal ganglion, $\mathrm{c}$ - spinal nerve, $d$ - notochord, e - centrum of vertebra

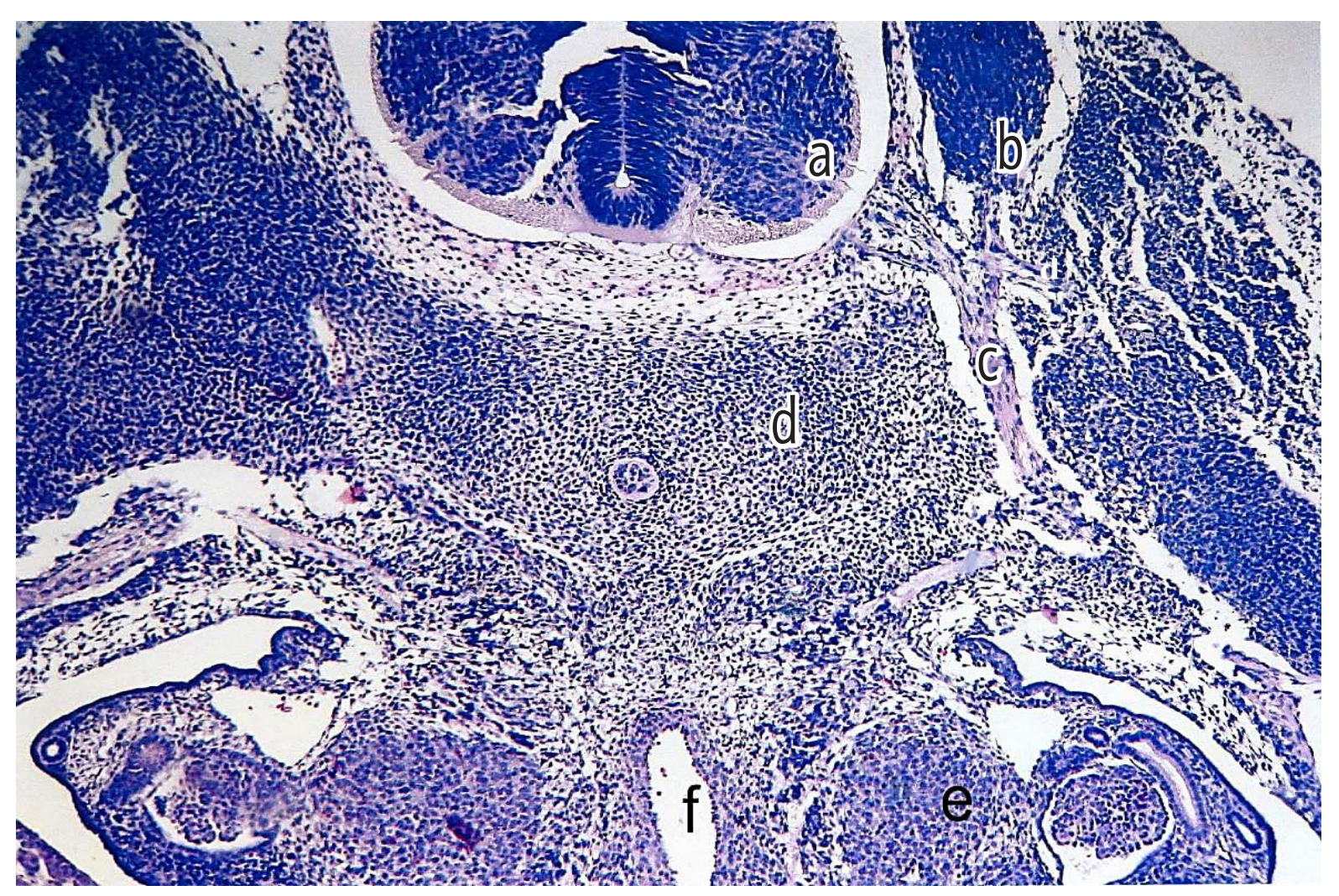

Figure 7. Horizontal section of embryo at stage $17 . \mathrm{H}+\mathrm{E}, \mathrm{x}$ 100. a - spinal nerve, $\mathrm{b}-$ spinal ganglion, $\mathrm{c}-$ spinal nerve, $\mathrm{d}$ - centrum of vertebra, e suprarenal gland, $\mathrm{f}$ - aorta 


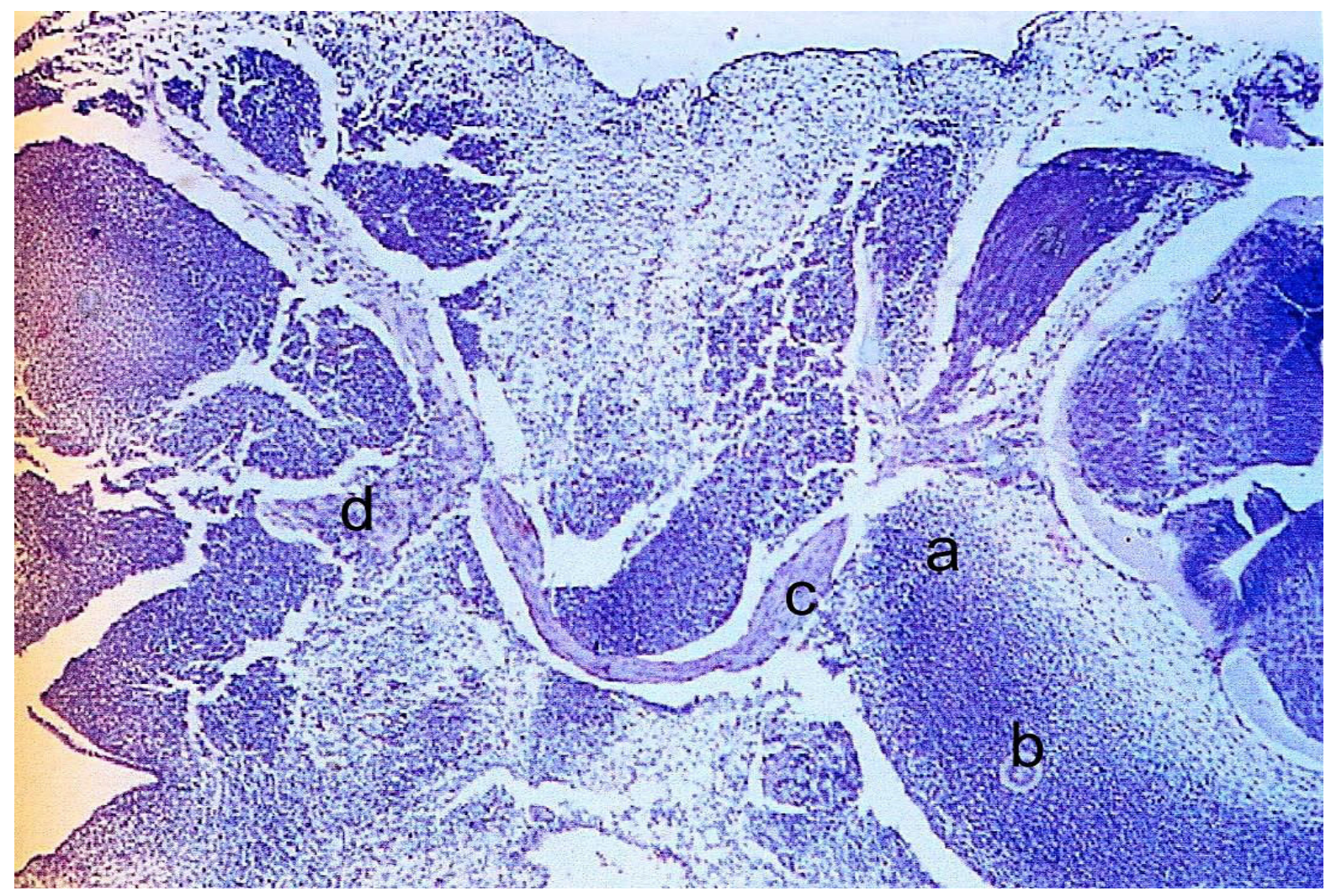

Figure 8. Horizontal section of embryo at stage 15. Cresyl violet, x 100. a - annulus fibrosus, b- nucleus pulposus around the notochord, $\mathrm{c}-$ spinal nerve, $d$ - upper limb

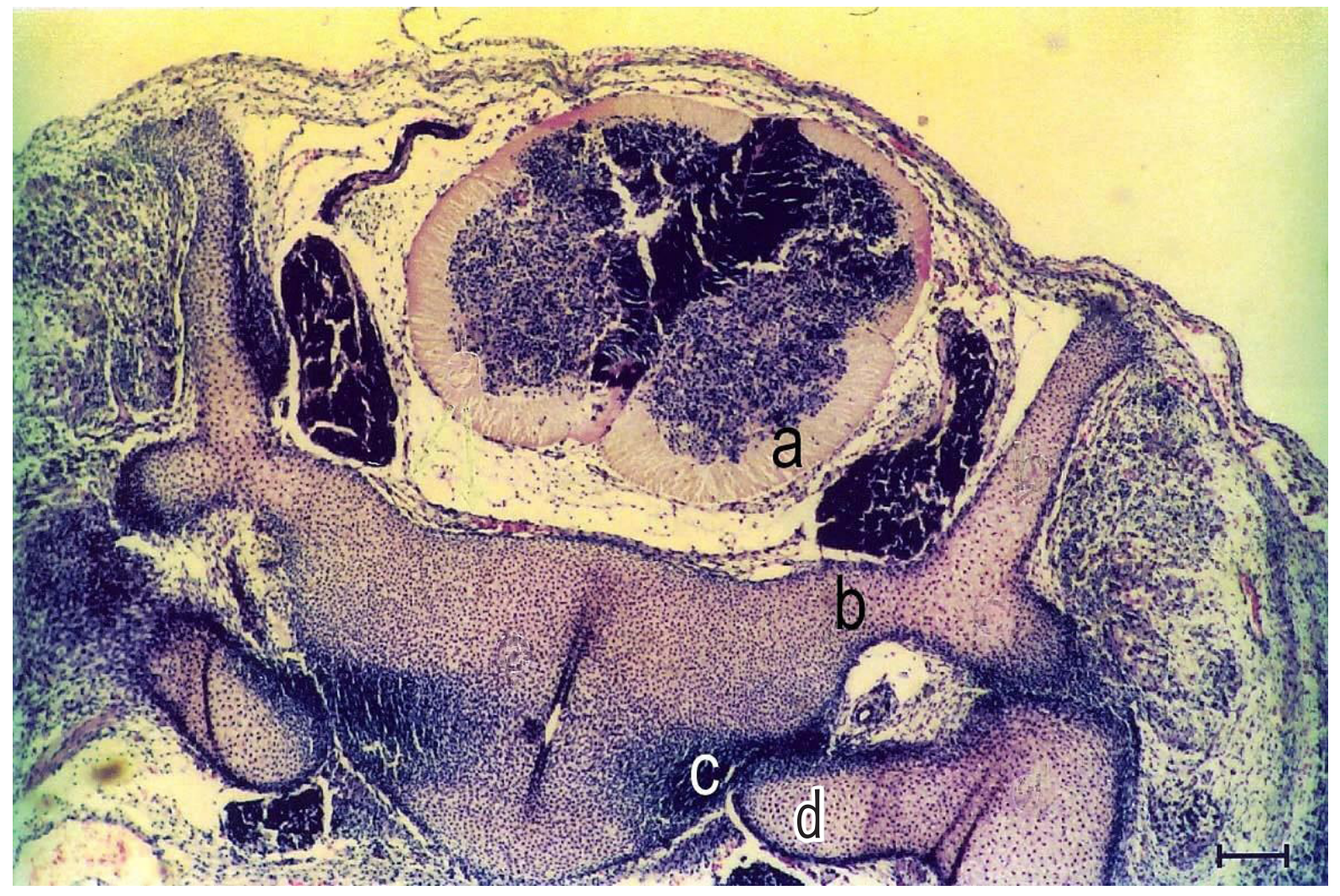

Figure 9. Horizontal section of embryo at stage 19. Cresyl violet, x 100. a - spinal cord, b - neural arch, c - annulus fibrosus, $d$ - head of rib 


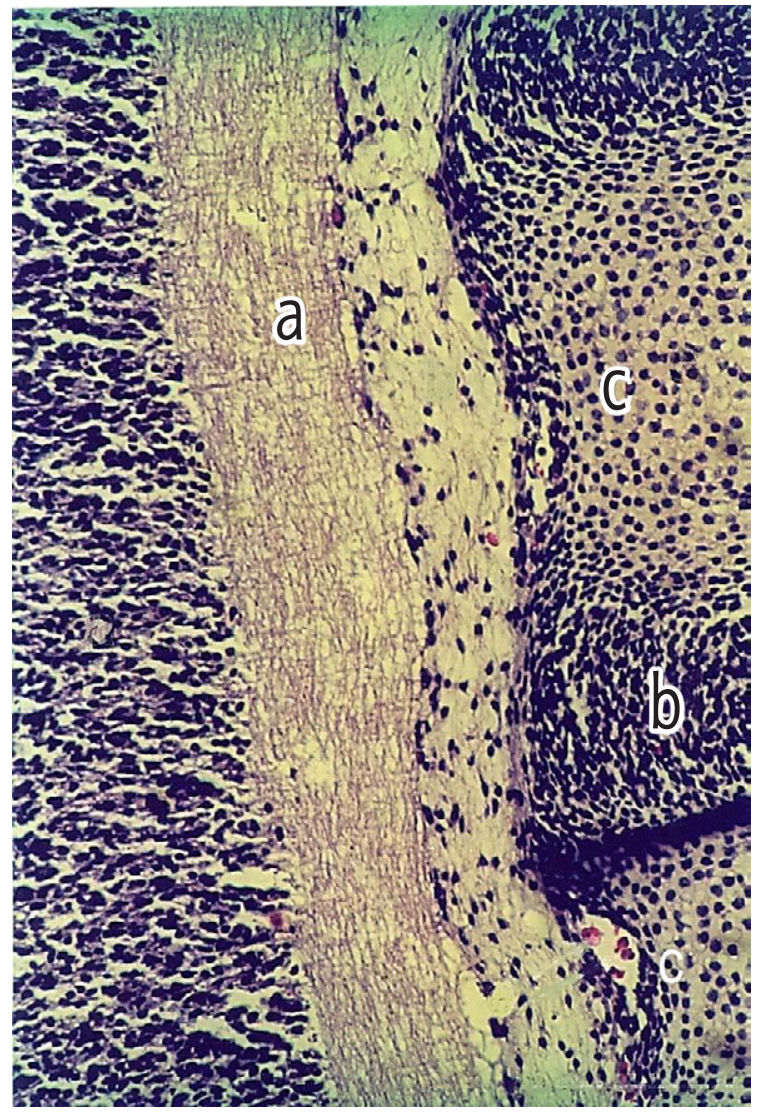

Figure 10. Sagittal section of embryo at stage 19. Cresyl violet, x 400 . a - spinal cord, $b$ - annulus fibrosus, $c$ - vertebral body

densely packed cells. In the lateral zone, which is smaller, cells are more loosely packed and arranged in circular rows. These rows are particularly evident in the lateral margins of the annulus fibrosus (Figure 8). Such arrangement is considered as the initial stage of lamellar structure of the annulus fibrosus. It may be concluded then that the laminar structure of the intervertebral disc begins in embryos at stage 15 in the cervical and thoracic parts. The height of the intervertebral disc differs in its posterior and anterior parts. The disc is of the same vertical diameter as the vertebral body in the posterior part and decreases toward the anterior part where it measures $40 \%$ of the whole vertebral unit.

With advancement of embryonic development this lamellar arrangement of the annulus fibrosus proceeds from periphery of the disc toward nucleus pulposus and in embryos of stage 19 (46 days) it is distinct in the whole annulus fibrosus (Figures 9,10 ). In sagittal section of the vertebral column in embryos of stage 19 the intervertebral discs are narrow as compared to vertebral bodies and they are bulging anteriorly and posteriorly (Figure 11). The vertical diameter of the inter-

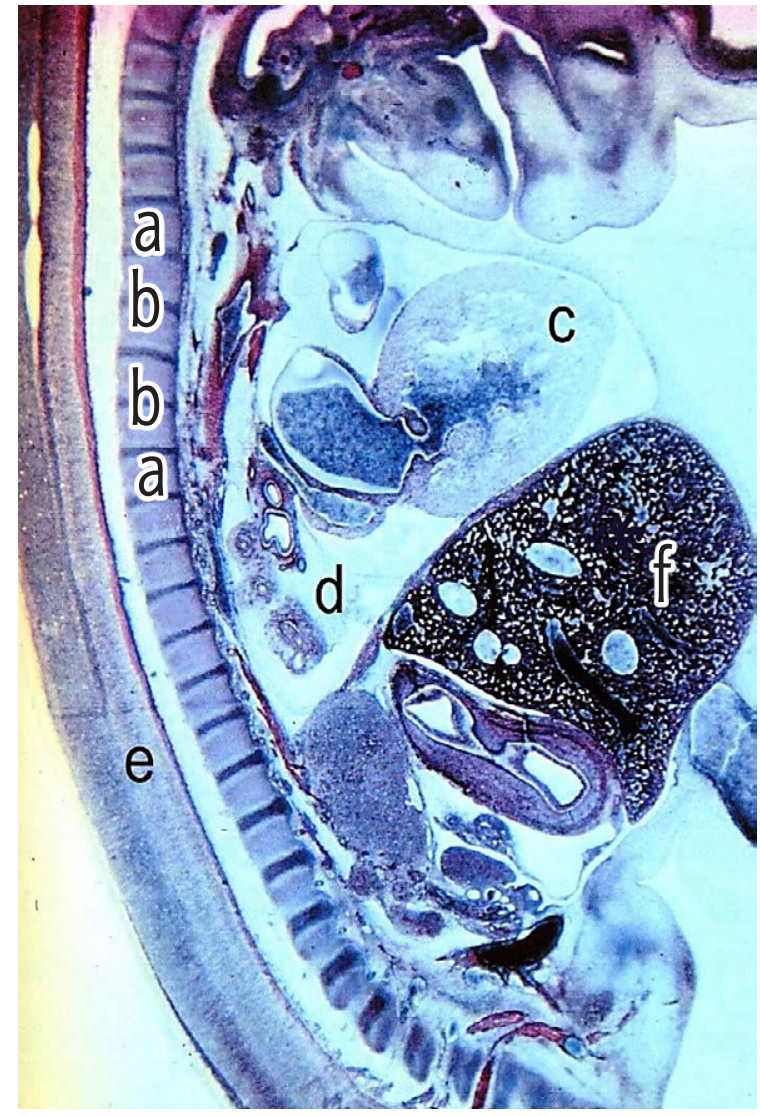

Figure 11. Sagittal section of embryo at stage 19. Mallory stain, $x 25$. a - vertebral body, b-intervertebral disc, c - heart, d - lung, e - spinal cord, $f$ - liver

vertebral disc in the cervical, thoracic and lumbar parts of the vertebral column constitutes one third of the height of the vertebral body. At the level of the intervertebral disc the notochord presents cellular aggregations. By the end of the embryonic period the nucleus pulposus shifts dorsally.

\section{Discussion}

The development of the vertebral column is preceded by that of the somites and the notochord [17]. The development of the individual vertebrae begins with a Shh-mediated induction by the notochord cells on the somite in order to form the sclerotome. Other signaling pathways which participate in formation of vertebrae include the BMP, WNT, Pax1 and HOX signaling systems $[3,18,19]$. Pax 1 gene plays an important role and it is continuously expressed during the development of the intervertebral disc in embryogenesis. This gene encodes transcriptional factors that regulate and take part in vertebrae formation. It is believed that Pax 1 and the subsequent formation of the intervertebral 
disc is an important factor in maintaining the segmental character of the vertebral column [20-22].

Several investigators have described the contribution of the loose and dense zones of sclerotomes to formation of the vertebrae and intervertebral discs. Bardeen [23] concluded that the vertebral body and intervertebral disc develop from both sclerotomites. In Prader's theory of vertebral resegmentation, condensed caudal and loose cranial sclerotomites are formed and both differentiate into vertebral body and disc [11, 12]. This theory was also supported by Sensenig [13] and Peacock [15].

More recently the theory of resegmentation of sclerotomes has been denied $[14,17,24]$ and it is postulated that the dense zones give rise to the intervertebral discs and take part in the formation of ribs and neural arches, whereas the loose zones and perinotochordal sheath form vertebral body.

The key structure in the development of the intervertebral disc is the notochord, which provides the template for the development of the disc $[15,25,26]$. This rod-like axial structure induces differentiation of mesoderm into sclerotomes.

In the present study it was shown that in the early stages (13 and 14) the notochord is a continuous structure of the same diameter in the loose and dense zones of sclerotomes. Beginning from stage 15 (36 days) the notochord is progressively thicker in the dense sclerotomite which gives origin to intervertebral disc. The period of formation of laminae in the annulus fibrosus during development markedly differs among investigators.

Peacock [15] who expressed age of embryos and fetuses basing on length observed intervertebral expansions of the notochord in embryos at $21 \mathrm{~mm}$ what corresponds to Carnegie stage 21 (51 days). The concentric arrangement of cells in the annulus fibrosus he observed in embryos at $10 \mathrm{~mm}$ what corresponds to Carnegie stage 16 (39 days).

It has to be stressed that the lamellar arrangement of the annulus fibrosus is accompanied by expansions of the notochord in the intervertebral disc. Such expansions we observed in the present study in embryos of stage 15 (36 days).

O'Rahilly and Meyer [14] noted that the intervertebral discs were evident peripherally as the annuli fibrosi during embryonic period but they do not give precise stage during which differentiate laminae in the annulus fibrosus.

Lohse et al [27] wrote that the annulus fibrosus and nucleus pulposus of the intervertebral disc were identi- fied by 6 months of age and were similar in structure to those of the adult.

The present study performed on staged human embryos with precisely determined age proved that the laminar structure of the annulus fibrosus begins early in the sixth week of embryonic development.

With completion of growth, the vertical diameter of the intervertebral discs diminishes. It was shown by Popova-Latkina [28]. She found that to the end of sixth week the intervertebral disc is one third the height of the adjacent vertebral body. At the beginning of the third month the disc is only one sixth the height of the vertebral body.

In the present investigations in embryos of seventh week the intervertebral disc was one third the height of the vertebral body.

Brandner [29] investigated values of the vertebral body and intervertebral disc index in newborns and adolescents. He found that an index between the disc and the next lower vertebral body height decreases significantly after the first month and is almost stable until 12 years when it decreases once more.

\section{Acknowledgements}

\section{Conflict of interest statement}

The authors declare that there is no conflict of interest in the authorship or publication of contribution.

\section{Funding sources}

There are no sources of funding to declare.

\section{References}

1. Pattappa G, Li Z, Peroglio M, Wismer N, Alini M, Grad S. Diversity of intervertebral disc cells: phenotype and function. J Anat. 2012;221:480-496.

2. Humzah MD, Soames RW. Human intervertebral disc: structure and function. Anat Rec. 1988;220:337-356.

3. Henrikson HB, Brisby $\mathrm{H}$. Development and regeneration potential of the mammalian intervertebral disc. Cells Tissues Organs. 2013;197(1):1-13.

4. Grunhagen T, Wilde G, Soukane DM. Nutrient supply and intervertebral disc metabolism. J Bone Joint Surg Am. 88 (suppl 2):30-35.

5. Roberts S, Evans H, Trivedi J, Menage J. Histology and pathology of the human intervertebral disc. J Bone Joint Surg Am. 2006;88(suppl 2):10-14.

6. Nosikova YS, Santerre JP, Grynpas M, Gibson G, kandel RA. Characterization of the annulus fibrosus - vertebral body interface: identification of new structural features. J Anat. 2012;221:577-589.

7. Buckwalter JA. Aging and degeneration of the human intervertebral disc. Spine. 1995;20:1307-1314.

8. Mwale F, Roughley P, Antonion J. Distinction between the extracellular matrix of the nucleus pulposus and hyaline cartilage: a requisite for tissue angineering of intervertebral disc. Eur Cell Mater. 2004;8:58-63. 
9. Pezowicz CA, Robertson PA, Broom ND. Intralamellar relationships within the collagenous architecture of the annulus fibrosus imaged in its fully hydrated state. J Anat. 2005;207:299-312.

10. Yu J, Winlove PC, Roberts S. Elastic fibre organization in the intervertebral discs of the bowine tail. J Anat. 2002; 201:465-475.

11. Prader A. Die Frühembryonale Entwicklung der menschlichen Zwischenwirbelscheibe. Acta Anat. 1947;3:68-83.

12. Prader A. Die Entwicklung der Zwischenwirbelscheibe beim menschlichen Keimling. Acta Anat. 1947;3: 115-152.

13. Sensenig EC. The early development of the human vertebral column. Contr Embryol Carneg Instn. 1949;33: 21-41.

14. O'Rahilly R, Meyer DB. The timing and sequence in the development of the human vertebral column during the embryonic period proper. Anat Embryol. 1979;157: 167-176.

15. Peacock A. Observations on the pre-natal development of the intervertebral disc in man. J Anat. 1951;85: 260-274.

16. Pezowicz CA, Robertson PA, Broom ND. The structural basis of interlamellar cohesion in the intervertebral disc wall. J Anat. 2006;208:317-330.

17. O'Rahilly $R$, Benson DR. The development of the vertebral column. In: Bradford DS, Hensinger RM, editors. The pediatric spine. New York, Thieme; 1985; 3-17.

18. Day TF, Guo X, Garret-Beal L, Yang Y. Wnt/beta-catenin signaling in mesenchymal progenitors controls osteoblast and chondrocyte differentiation during vertebrate skeletogenesis. Dev Cell. 2005;8:739-750.

19. Mundy C, Yasuda T, Kinumatsu T, Yamaguchi Y, Iwamoto $M$, Enomoto-Iwamoto M, et al. Synovial joint formation requires local Ext1 expression and heparan-sulfate production in developing mouse embryo limbs and spine. Dev Bbiol. 2011;351:70-81.

20. DiPaola CP, Farmer JC, Manova K, Niswander LA. Molecular signaling in intervertebral disc development. J Orthop res. 2005;23:1112-1119.

21. Risbud MV, Schaer TP, Shapiro IM. Toward an understanding of the role of notochordal cells in the adult interver- tebral disc: from discord to accord. Dev Biol. 2010;239: 2141-2148

22. Mansouri A, Hallonet M, Gruss P. Pax genes and their roles in cell differentiation and development. Cur Opin Cell Biol. 1996;8(6):851-857.

23. Bardeen CR. The development of the thoracic vertebrae in man. Amer J Anat. 1905;4:163-174.

24. Grzymisławska M, Woźniak W, Łupicka J, Skórzewska A. The development of the vertebral column in human embryos during fifth week (developmental stages 13-15). Now Lek. 2012;81(6):596-604.

25. Fleming A, Keynes RJ, Tannahill D. The role of the notochord in vertebral column formation. J Anat. 2001;199: 177-180.

26. Hunter CJ, Matyas JR, Duncan NA. Cytomorphology of notochordal and chondrycytic cells from the nucleus pulposus: a species comparison. J Anat. 2004;205:357-362.

27. Lohse CL, Hyde DM, Benson DR. Comparative development of thoracic intervertebral discs and intra-articular ligaments in the human, monkey, mouse and cat. Acta Anat. 1985;122:220-228.

28. Popova-Latkina NV. Etwicklung der Zwischenwirbelscheiben und der Chorda in der Embryonalzeit beim Menschen. Anat Anz. 1967;121(5):518-536.

29. Brandner ME. Normal values of the vertebral body and intervertebral disc index during growth. Radiology. 1970; 110(3):618-627.

Acceptance for editing: 2015-02-10 Acceptance for publication: 2015-03-30

Correspondence address:

Małgorzata Grzymisławska Department of Anatomy Poznan University of Medical Sciences 6 Święcicki Str., 60-781 Poznań, Poland phone: +48 618546564 fax: +48618546568 email: malgorzatagrzymislawska@ump.edu.pl 